\title{
Comment on the Paper by Uerlich et al: Obesity Management in Europe: Current Status and Objectives for the Future. Obes Facts 2016;9:273-283
}

\author{
Vojtech Hainer ${ }^{a} \quad$ Constantine Tsigos ${ }^{b}$ Hermann Toplak ${ }^{c}$ Dragan Micic ${ }^{d}$ \\ a Obesity Management Center, Institute of Endocrinology, Prague, Czech Republic; \\ ${ }^{b}$ Department of Nutrition and Dietetics, Harokopio University, Athens, Greece; ${ }^{c}$ Department \\ of Internal Medicine, Medical University of Graz, Graz, Austria; d Medical Faculty, University \\ of Belgrade, Belgrade, Serbia
}

\section{Surveys on Obesity Management in Europe}

The recently published paper entitled 'Obesity management in Europe: current status and objectives for the future' (Obes Facts 2016;9:273-283) summarizes the results of a survey on obesity management conducted in 23 member countries of the European Association for the Study of Obesity (EASO) [1]. The team of authors includes experts both in obesity management and in obesity prevention and emphasizes the important role of preventive measures in changing the obesogenic environment to a leptogenic one and thus contributing to the improvement of obesity management across Europe.

This is the third survey on obesity management in EASO member countries. The two previous surveys prepared by the Obesity Management Task Force (OMTF) of the EASO were conducted in 2003 [2] and 2007 (unpublished results). All surveys showed insufficient care of obese patients across Europe although the questions addressed to obesity experts differed between them. Moreover, in the previous surveys representatives of the national obesity associations (presidents or vice-presidents) filled the questionnaire after consultation with members of the National Executive Committees, while the survey by Uerlich et al. [1] included a broad spectrum of participants (e.g. researchers, general or specialized physicians, dietitians, psychologists, exercise physiologists, and social workers) who were invited to participate by the presidents of the national obesity associations. 
Hainer et al.: Comment on the Paper by Uerlich et al: Obesity Management in Europe: Current Status and Objectives for the Future. Obes Facts 2016;9:273-283

\section{Failure in the Implementation of Guidelines on Obesity Management}

Uerlich etal. [1] stressed the role of guidelines in the implementation of effective measures in obesity management. The first comprehensive guidelines on obesity managementappeared in the 1990s. In 2003, the first European survey among EASO members established that national guidelines were available in 18 of 24 member countries [2], but all representatives of the national obesity associations recommended to prepare European guidelines. In response to this call, the first European guidelines on obesity management were published in 2004 [3]. These guidelines, developed by the EASO OMTF and based on 13 existing national obesity guidelines, addressed in particular primary care physicians and emphasized mainly the role of common rules in obesity management. A recently published EASO position statement on multidisciplinary obesity management in adults briefly summarizes the main principles in the care of obese adults [4]. All above mentioned recommendations provide just essential information on principles of obesity management. However, several more comprehensive guidelines on both obesity management and on bariatric surgery have been published and frequently translated to national languages of the EASO member countries [5-7]. In addition, more extensive guidelines on obesity management have recently been published both in Europe [8] and the USA [9]. Uerlich et al. [1] consider currently available guidelines too long and elaborate for daily use and report several reasons for the failure in implementing these guidelines [1]. The absence of efficient multidisciplinary teams and multi-level networks in obesity management may certainly play a crucial role. Thus, specialized obesity management centers should have a unique position in coordination of obesity management and guideline implementation. In 2007, such specialized centers existed in 15 out of 18 EASO member countries, as reported by national obesity associations, and their number highly varied across Europe. Some of them which fulfilled the EASO criteria joined later a network of EASO-Collaborating Centers for Obesity Management (COMs) [10], together with many others over time to reach by now the number of 70 from 32 professional membership associations across Europe.

\section{Involvement of Physicians in the Care of Obese Patients}

According to the first EASO OMTF survey carried out in 18 EASO member countries in 2003 [2], different physicians were involved in the care of obese patients:

- obesity specialists in $94 \%$ of countries,

- general practitioners (GPs) in $89 \%$ of countries,

- other physicians in $44 \%$ of countries.

GPs were mainly engaged in obesity management in $50 \%$ countries, obesity specialists in $32 \%$ countries and other physicians in $18 \%$ countries. The second EASO OMTF survey conducted in 2007 in 24 EASO member associations confirmed that in most countries, obesity management is in the hands of GPs or other physicians (e.g. internists, endocrinologists/ diabetologists, cardiologists, gynecologists) with no specialized expertise in obesity management. Moreover, funding for GP's care of obese patients in European countries widely differed. It was provided either by health insurance $(36 \%)$ or government $(36 \%)$ or paid privately by the individual (28\%). None of the responders to the survey rated the quality of care of obese patients provided by GPs as appropriate and gave several reasons: unsatisfactory treatment outcomes, inadequate reimbursement for the time demanding care, poor knowledge about obesity, and underestimation of obesity as a disease by both public and health care providers. In the same survey, $96 \%$ of responders supported engagement of obesity specialists in the care of obese patients as well as the need for specialized obesity 
Hainer et al.: Comment on the Paper by Uerlich et al: Obesity Management in Europe: Current Status and Objectives for the Future. Obes Facts 2016;9:273-283

training. In some countries, however, there are many individuals and institutions that declare themselves as obesity specialists, obesity centers or clinics, but frequently without appropriate expertise. Moreover, some of them use ineffective or potentially harmful treatment procedures.

A recent survey conducted among 2,022 US primary care physicians revealed that almost two-thirds felt that they lack effective strategies to help obese patients although they felt a responsibility to promote weight-related care [11]. A similar national survey from the USA reported that primary care physicians perceive the lack of patient motivation as the greatest barrier in the successful obesity management, while they feel that better knowledge of obesity management and positive attitudes towards it among physicians may contribute to a better outcome [12]. Another study conducted among family physicians described a general sense of frustration in managing obesity - resulting from poor reimbursement for the timedemanding treatment, a lack of self-efficacy, and many factors that were perceived as beyond the physician's control [13]. Finally, a recent international study [14] addressed 335 clinicians who cared for obese patients in order to investigate their attitudes and practices in obesity management. Approximately half of the participants were based in Europe, most of them were nutritionists $(26.0 \%)$, obesity specialists $(19.1 \%)$, and endocrinologists/diabetologists $(17.0 \%)$. It is not surprising that these experts were confident in their ability to manage obesity effectively. However, they reported that most of their patients were unable to achieve their weight loss goals. Although participants emphasized a need for comprehensive multidisciplinary obesity management, only $72 \%$ had access to a dietitian, and most of them had limited access to services by psychologists/psychiatrists, exercise physiologists, specialist nurses etc. Rather low was also the access to a bariatric surgeon (32\%), pharmacotherapy (37\%) and meal replacement (26\%). Surprisingly, the lowest access to pharmacotherapy was in Europe (28\%) and North America (14\%). As expected, the access to most services was much higher among obesity specialists.

\section{Who Are Obesity Specialists?}

Multiple surveys and obesity management strategies included obesity specialists or physicians with special training in obesity management in the care of obese patients $[3,5,8$, 10]. As reported by Uerlich et al. [1], 'specialists are often not specifically specialized in obesity'. Moreover, no concrete definition of obesity specialists has been provided nor the conditions required for their practice. Notably, obesity specialists engaged in EASO COMs were required to be physicians with special training in obesity management, e.g., SCOPE fellows or other physicians with comparable knowledge, skills, and competence as documented by a structured CV; specific clinical research experience and training were also expected [10].

No doubt, an obesity specialist should be a physician with expertise in the sub-specialty of obesity medicine (obesitology). He/she should be a partner of health authorities including the health insurance companies in the implementation of the obesity management program in daily medical practice. Nowadays it is not popular to create new medical sub-specialties which usually lead to further splitting of the current medicine. Nevertheless, obesity medicine is not about splitting but about connecting not only medical but also other related disciplines.

In the USA, a country with one of the highest prevalences of obesity, a sub-specialization in obesity medicine was initiated 4 years ago when The American Board of Obesity Medicine was established with American Society of Bariatric Physicians, The Obesity Society, Columbia University Institute of Human Nutrition, and Harvard Medical School Blackburn Course in Obesity Medicine as primary continuing medical education partners [15]. Nowadays, over 
Hainer et al.: Comment on the Paper by Uerlich et al: Obesity Management in Europe: Current Status and Objectives for the Future. Obes Facts 2016;9:273-283

1,600 American doctors obtained a certificate for obesity specialist [15]. However, whether or not to follow Americans and to establish obesity medicine ('obesitology') as a novel medical discipline in Europe should be seriously considered. Both experts and health authorities in each particular country should take into account the locally available educational system in postgraduate medicine as well as specific human and financial resources. Specialist weight management for severe and complex obesity is now accepted in the UK health system [16]. However, it is emphasized that there is no single stakeholder willing to take overall responsibility for obesity care. Perhaps, obesity management centers together with certified obesity specialists could play this role in the future.

\section{Voluntary and Commercial Weight Management Groups}

It is obvious that no health care system can afford to take care of all overweight and obese individuals. Many overweight individuals and subjects with uncomplicated obesity can obtain appropriate care in voluntary or commercial weight loss groups. Even in 2003, most EASO member countries $(90 \%)$ had both voluntary and commercial weight management groups, whereas work-site groups were reported only in 4 countries [2]. It can be assumed that nowadays an accessibility of weight loss groups has substantially increased across Europe. Cognitive behavioral therapy applied in groups may significantly increase motivation of obese patients to be actively involved in obesity management. In addition, more information for changing lifestyle could be provided for obese patients through educational materials, books, TV, and other media, but only delivered by competent experts

\section{Conclusion}

Uerlich et al. [1] appeal in their paper for more emphasis on the long-term multidisciplinary approaches and on the collaboration between health care providers in obesity management. This demand is in agreement with other reported experiences in obesity management. Recently, a need for introducing certified obesity specialists in the care of obese patients has been raised. Obesity specialists together with obesity management centers should ensure evidence-based approach across the obesity management networks and should communicate, as acknowledged partners, with health care authorities and insurance companies about obesity prevention and treatment.

\section{Acknowledgements} Republic

Supported by the Czech Ministry of Health - project 00023761 Institute of Endocrinology, Prague, Czech

\section{Disclosure Statement}

The authors declare no conflict of interest 
Hainer et al.: Comment on the Paper by Uerlich et al: Obesity Management in Europe: Current Status and Objectives for the Future. Obes Facts 2016;9:273-283

\section{References}

1 Uerlich MF, Yumuk V, Finer N, Basdevant A, Visscher TLS: Obesity management in Europe: current status and objectives for the future. Obes Facts 2016;9:273-283.

2 Hainer V: Current perspectives on obesity management in Europe; in EASO OMTF Papers and Guidelines: Report on Current Status and Perspectives in Obesity Management. IOTF Position Paper - September 2003. http://easo.org/task-forces/obesity-management-omtf/ (last accessed November 14, 2016).

3 Hainer V, Finer N, Tsigos C, Basdevant A, Carruba M, Hancu N, Mathus-Vliegen L, Schutz Y, Zahorska-Markiewicz B, Scarrott F: Management of obesity in adults: project for European primary care. Int J Obes Relat Metab Disord 2004;28(suppl 1):S226-S231.

4 Yumuk V, Frühbeck G, Oppert JM, Woodward E, Toplak H, for the Executive Committee of the European Association for the Study of Obesity: An EASO position statement on multidisciplinary obesity management in adults. Obes Facts 2014;7:96-101.

5 Tsigos C, Hainer V, Basdevant A, Finer N, Fried M, Mathus-Vliegen E, Micic D, Maislos M, Roman G, Schutz Y, Toplak H, Zahorska-Markiewicz B; Obesity Management Task Force of the European Association for the Study of Obersity: Management of obesity in adults: European clinical practice guidelines. Obes Facts 2008;1:106116.

6 Fried M, Hainer V, Basdevant A, Buchwald H, Deitel M, Finer N, Greve JWM, Horber F, Mathus-Vliegen E , Scopinaro N, Steffen R, Tsigos C, Weiner R, Widhalm K: Interdisciplinary European guidelines on surgery of severe obesity. Obes Facts 2008;1:52-59.

7 Fried M, Yumuk Y, Oppert JM, Scopinaro M, Torres AJ, Weiner J, Yashkov Y, Fruhbeck G: Interdisciplinary European guidelines on metabolic and bariatric surgery. Obes Facts 2013;6:449-468.

8 Yumuk V, Tsigos C, Fried M, Schindler K, Busetto L, Micic D, Toplak H, for the Obesity Management Task Force of the European Association for the Study of Obesity: European guidelines for obesity management in adults. Obes Facts 2015;8:402-424.

9 Jensen MD, Ryan DH, Apovian CM et al: 2013 AHA/ACC/TOS guideline for the management of overweight and obesity in adults: a report of the American College of Cardiology/American Heart Association Task Force on Practice Guidelines and The Obesity Society. Circulation 2014;129(25 suppl 2):S102-138.

10 Tsigos C, Hainer V, Basdevant A, Finer N, Mathus-Vliegen E, Micic D, Maislos M, Roman G, Schutz Y, Toplak H, Yumuk V, Zahorska Markiewicz B, for the Obesity Management Task Force of the European Association for the Study of Obesity: Criteria for EASO-collaborating centres for obesity management. Obes Facts 2011;4:329_ 333.

11 Steeves JA, Liu B, Willis G, Lee R, Smith AW: Physicians' personal beliefs about weight-related care and their associations with care delivery: the U.S. National Survey of energy balance related care among primary care physicians. Obes Res Clin Pract 2015;9:243-255.

12 Salinas GD, Glauser TA, Williamson JC, Rao G, Abdolrasulnia M: Primary care physicians attitudes and practice in the management of obese adults: results from a national survey. Postgrad Med 2011;123:214-219.

13 Epling JW, Morley CP, Ploutz-Snyder R: Family physician attitudes in managing obesity: a cross-sectional survey study. BMC Res Notes 2011;4:473.

14 Leiter LA, Astrup A, Andrews RC, Cuevas A, Horn DB, Kunešová M, Wittert G, Finer N: Identification of educational needs in the management of overweight and obesity: results of an international survey of attitudes and practice. Clin Obes 2015;5:245-255.

15 American Board of Obesity Medicine. http://abom.org (last accessed November 14, 2016).

16 Capehorn MS, Haslam DW, Welbourn R: Obesity treatment in the UK Health system. Curr Obes Rep 2016;5: 320-326. 